\title{
Murine models of Pneumocystis infection recapitulate human primary immune disorders
}

\author{
Waleed Elsegeiny, ${ }^{1,2,3}$ Mingquan Zheng, ${ }^{1,2}$ Taylor Eddens, ${ }^{1,2,3}$ Richard L. Gallo, ${ }^{4}$ Guixiang Dai, ${ }^{5}$ \\ Giraldina Trevejo-Nunez, ${ }^{1,2}$ Patricia Castillo, ${ }^{1,2,3}$ Kara Kracinovsky, ${ }^{1,2}$ Hillary Cleveland, ${ }^{1,2}$ \\ William Horne, ${ }^{1}$ Jonathan Franks, ${ }^{6}$ Derek Pociask, ${ }^{5}$ Mark Pilarski, John F. Alcorn, ${ }^{2}$ Kong Chen, ${ }^{1,2}$ \\ and Jay K. Kolls ${ }^{1,2,5}$ \\ 'Richard King Mellon Foundation Institute for Pediatric Research and 'Department of Pediatrics, Children's Hospital \\ of Pittsburgh of University of Pittsburgh Medical Center, Pittsburgh, Pennsylvania, USA. ${ }^{3}$ Department of Immunology, \\ University of Pittsburgh School of Medicine, Pittsburgh, Pennsylvania, USA. ${ }^{4}$ Department of Dermatology, UCSD, La Jolla, \\ California, USA. ${ }^{5}$ Department of Medicine, Tulane School of Medicine, New Orleans, Louisiana, USA. ${ }^{6}$ Center for Biologic \\ Imaging, University of Pittsburgh, Pittsburgh, Pennsylvania, USA.
}

Despite the discovery of key pattern recognition receptors and $\mathrm{CD} 4^{+} \mathrm{T}$ cell subsets in laboratory mice, there is ongoing discussion of the value of murine models to reflect human disease. Pneumocystis is an AIDS-defining illness, in which risk of infection is inversely correlated with peripheral CD4+ $\mathrm{T}$ cell counts. Due to medical advances in the control of HIV, the current epidemiology of Pneumocystis infection is predominantly due to primary human immunodeficiencies and immunosuppressive therapies. To this end, we found that every human genetic immunodeficiency associated with Pneumocystis infection that has been tested in mice recapitulated susceptibility. For example, humans with a loss-of-function IL21R mutation are severely immunocompromised. We found that IL-21R, in addition to CD4 ${ }^{+} \mathrm{T}$ cell intrinsic STAT3 signaling, were required for generating protective antifungal class-switched antibody responses, as well as effector $T$ cell-mediated protection. Furthermore, CD4 ${ }^{+} \mathrm{T}$ cell intrinsic IL-21R/STAT3 signaling was required for $\mathrm{CD}^{+} \mathrm{T}$ cell effector responses, including IL-22 production. Recombinant IL-22 administration to $/ 121 r^{-1-}$ mice induced the expression of a fungicidal peptide, cathelicidin antimicrobial peptide, which showed in vitro fungicidal activity. In conclusion, SPF laboratory mice faithfully replicate many aspects of human primary immunodeficiency and provide useful tools to understand the generation and nature of effector $\mathrm{CD} 4^{+} \mathrm{T}$ cell immunity.

Conflict of interest: The authors have declared that no conflict of interest exists.

Submitted: November 23, 2016

Accepted: May 17, 2018

Published: June 21, 2018

\section{Reference information:} JCI Insight. 2018;3(12):e91894. https://doi.org/10.1172/jici. insight.91894.

\section{Introduction}

The poor rate of reproducibility and translatability of experimental studies has been a major issue plaguing the scientific community for many years. This can be attributed to many factors, including inadequate experimental design and improper data and/or statistical analyses, as well as - in animal studies - difference in housing, microbiome, and more (1-3). Fortunately, a plethora of initiatives and measures by the $\mathrm{NIH}$ and publishers are continuously being implemented to enhance the reliability of scientific findings (4-6). However, there has also been some scrutiny and debate as to the use of murine models - or, more specifically, laboratory-bred mice — in their ability to recapitulate human biology and disease $(7,8)$.

Some immunological studies demonstrating the differences or similarities between laboratory mice and humans may only apply to specific models of disease or focused aspects of the immune system. For example, the study of immune requirements for protection from Pneumocystis murina ( $P$. murina) infection in mice and humans successfully recapitulate each other. Briefly, Pneumocystis jiorveci (the species that infects humans) is an opportunistic fungal pathogen that affects $\mathrm{HIV}^{+}$and non-HIV immunocompromised populations (7, 9-13). The emergence of Pneumocystis pneumonia as an AIDS-defining infection established the direct correlation of $\mathrm{CD}^{+} \mathrm{T}$ cell loss with susceptibility to infection $(14,15)$. This role has been validated numerous times in a variety of animal models, including nonhuman primates and laboratory mice housed under specific pathogen free (SPF) conditions. Restoration of $\mathrm{CD}^{+} \mathrm{T}$ cells in otherwise deficient patients or animals 
Table 1. Human genetic mutations associated with Pneumocystis infection that were recapitulated in mice

$\begin{array}{lc}\text { Genes associated w/ susceptibility in humans } & \text { Murine model } \\ \text { RAC1 } & + \\ \text { RAC2 } & + \\ \text { CD40 } & + \\ \text { TNFSF5 (CD40 ligand) } & + \\ \text { PRKDC } & + \\ \text { IL2RG } & + \\ \text { CD4 } & + \\ \text { HLA/MHCII } & + \\ \text { STAT3 } & + \\ \text { IL21R } & +\end{array}$

also restores the immunity against Pneumocystis spp. infection, which further demonstrates the importance of $\mathrm{CD} 4^{+} \mathrm{T}$ cells (16-20). However, the exact mechanism in which $\mathrm{CD}^{+} \mathrm{T}$ cells mediate Pneumocystis clearance is still unclear.

Through their production of effector cytokines, $\mathrm{CD}^{+} \mathrm{T}$ cells are believed to exert their dynamic functions by signaling to a range of target cells, including Pneumocystis-specific B cells, neutrophils, macrophages, eosinophils, and epithelial cells $(19,21-26)$. In mice and humans, activated $\mathrm{CD}^{+} \mathrm{Th}$ cells can be a subset into different lineages according to their cytokine production, as well as lineage-specific transcription factor expression. Th1 cells generate IFN- $\gamma$ and are required for controlling intracellular pathogens, including tuberculosis and influenza (27), while Th2 cells mainly produce IL-4, IL-5, and IL-13 for the eradication/control of parasites. IL-17A and IL-17F, essential host defense mediators against extracellular pathogens including $C$. albicans and $K$. pneumoniae, are key effector cytokines produced by Th17 cells (28-32). Follicular Th (Tfh) cells secrete high amounts of IL-21, which promotes antibody affinity maturation of germinal center (GC) B cells (29, 33-35). Recently, IL-21 has also been shown to directly promote Th2 cell function through its receptor, IL-21R (36), suggesting that IL-21 is a pleiotropic cytokine that regulates many aspects of the immune responses.

IL-21 signals through its heterodimeric receptor consisting of IL-21R and the common cytokine receptor $\gamma$ chain, and it activates the Janus family tyrosine kinases as well as members of the signal transducer and activator of transcription (STAT) protein family (37). IL-21 preferentially activates STAT3, although STAT1 and STAT5 activation by IL-21 have also been reported $(38,39)$. Interestingly, both IL21R- and STAT3-deficient humans are susceptible to $P$. jiroveci infection, indicating that an IL-21/STAT3 pathway may be critical for host defense against Pneumocystis (40-42). To investigate the involvement of this pathway and identify the molecular basis of IL-21/STAT3-mediated Pneumocystis clearance, we employed 2 well-established murine models, primary challenge model and adoptive transfer model, to define the $\mathrm{T}$ cell intrinsic molecules critical in $P$. murina clearance $(19,43)$. In contrast to recent findings that SPF mice did not recapitulate many aspects of human $\mathrm{CD}^{+} \mathrm{T}$ cell differentiation and distribution, both our models recapitulated the clinical cases and genetic susceptibility or $P$. jiroveci pneumonia (PJP) (7). Our findings are consistent with previous findings that Pneumocystis susceptibility in humans with primary immune deficiencies could be faithfully modeled by genetic models using laboratory mice with SPF husbandry (Table 1).

\section{Results}

STAT3 signaling in $C D 4^{+} T$ cells is required to mount successful immune responses to $P$. murina. We infected various cytokine and cytokine receptor-KO mice that have deficiencies in specific effector T cell lineages (Th1, Th2, and Th17) to discern which types of responses are required for protection during $P$. murina infection. Mice deficient in Il12b, Il4ra, Il23a, or Il17ra were infected with $P$. murina (isolated from congenic immunodeficient

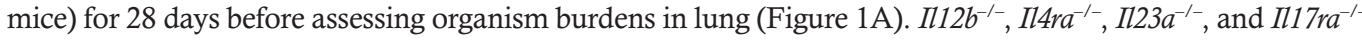
mice controlled infection equivalent to their WT controls (Figure 1, B and C), demonstrating that these cytokines are dispensable for fungal clearance. We then focused on broader factors that control Th cell differentiation, the intrinsic STAT family members. Although both Stat4-deficient (Th1) and Stat6-deficient (Th2) mice had slightly reduced rate of clearance of $P$. murina infection, Stat $3^{\text {fl/fl}} C D 4$-Cre transgenic mice were markedly susceptible to infection (Figure 1D). Moreover, to ensure STAT4 and STAT6 did not have complimentary roles, we infected mice deficient in both Stat4 and Stat6 (double KO [DKO] mice) and observed no gain in susceptibility to $P$. murina infection. However, DKO mice crossed to Stat $3^{\text {flfl }}$ CD4-Cre transgenic mice (triple $\mathrm{KO}$ [TKO] mice) were also susceptible, similar to $\mathrm{Rag}^{-1-} \mathrm{Il} 2 \mathrm{gC}^{-1-}$ positive control mice (Figure 1E), further demonstrating the crucial role of STAT3 in T cells.

To assess $\mathrm{CD}^{+} \mathrm{T}$ cell-specific effector function in the absence of B cell immunity, we adoptively transferred purified $\mathrm{CD}^{+}$splenocytes into $\mathrm{Rag} 1^{-/-}$mice prior to infection. Rag $1^{-/-}$mice received WT or $\mathrm{KO} \mathrm{CD} 4^{+} \mathrm{T}$ cells 2 weeks prior to a standard course of $P$. murina infection (Figure $1 \mathrm{~F}$ ). STAT3-deficient, $\mathrm{CD}^{+} \mathrm{T}$ cells had a significant impairment in mediating a successful fungal response compared with WT CD4 ${ }^{+} \mathrm{T}$ cells (Figure 1G). However, Rorc $^{-1-} \mathrm{CD}^{+} \mathrm{T}$ cells were fully capable of driving a significant 
A

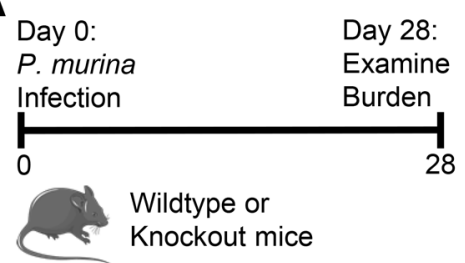

B
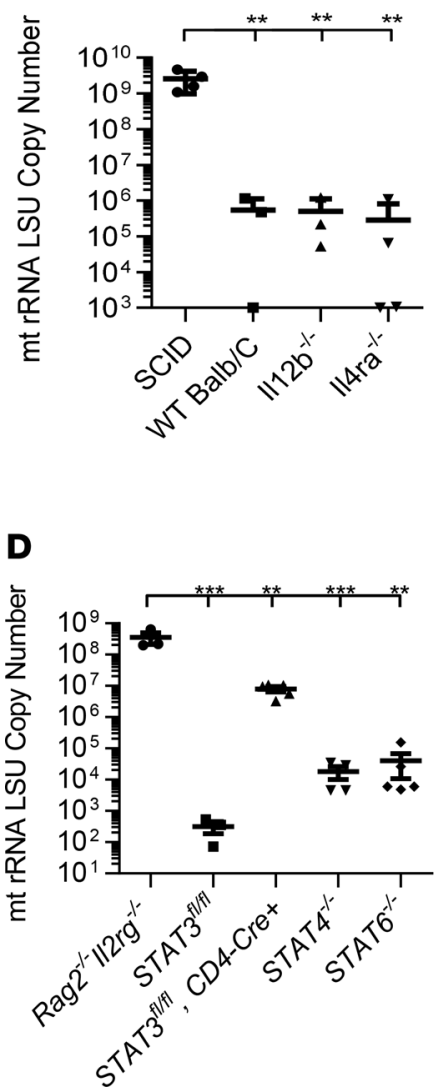

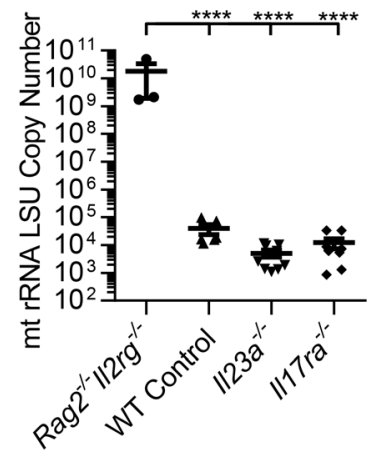

E

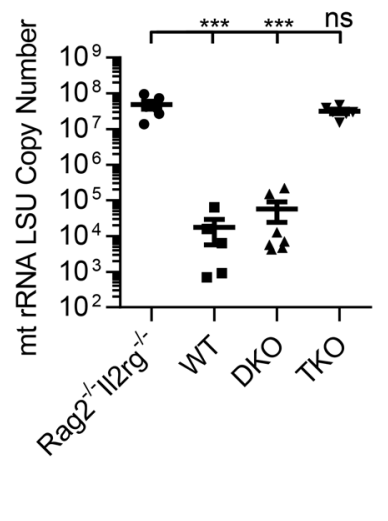

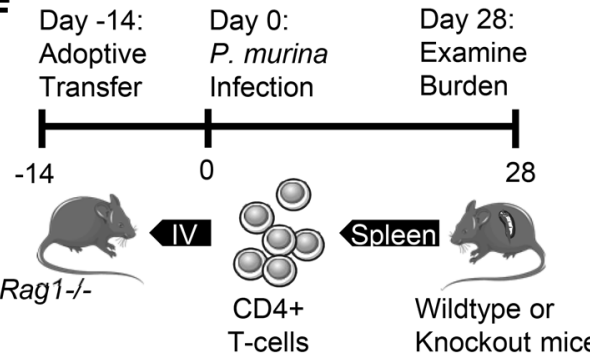

G

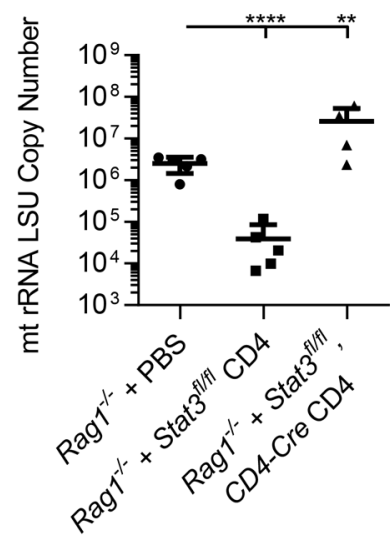

H

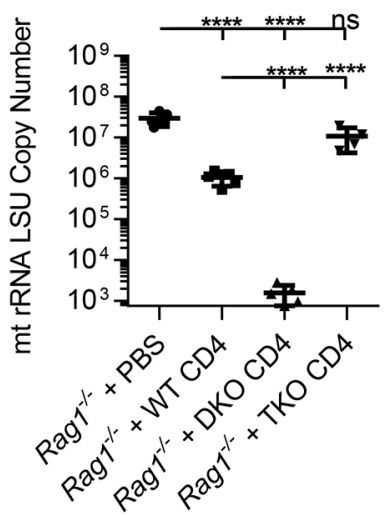

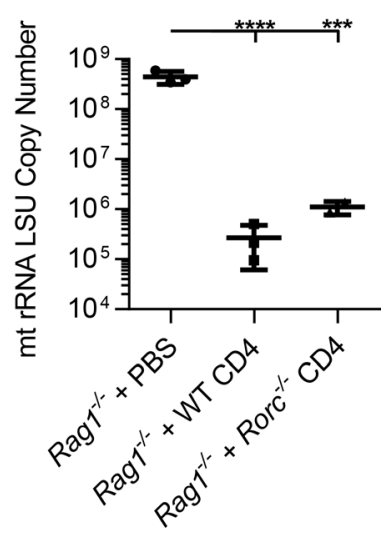

Figure 1. CD4 ${ }^{+}$T cell STAT3 signaling is required for Pneumocystis clearance. For primary infection model, WT and KO mice were infected for 4 weeks with $2 \times 10^{5}$ P. murina asci. (A) Schematic timeline of primary infection model. (B-E) Real-time PCR of whole lung RNA for $P$. murina mitochondrial ribosomal RNA large subunit (LSU) was performed and quantified to assess degree of $P$. murina burden. SCID, severe combined immunodeficiency; DKO, double KO; TKO, triple KO. For the T cell intrinsic model, WT and KO CD4+ T cells were adoptively transferred via i.v. injection to Rag $1^{-1-}$ mice 2 weeks prior to primary infection. (F) Schematic timeline of T cell intrinsic model. (G-I) Real-time PCR of whole lung RNA for $P$. murina mitochondrial ribosomal RNA large subunit was performed and quantified to assess degree of $P$. murina burden, reported as means \pm SEM for $n=4-6$ per group. B and $\mathbf{C}$ were not repeated. D, E, and G-I are representatives of 2 experiments. $P$ values are annotated as follows: ${ }^{* *} P \leq 0.01,{ }^{* * *} P \leq 0.001$, and ${ }^{* * * *} P \leq 0.0001$ (1-way ANOVA).

reduction in fungal burden; this result suggests a Th17-independent role for STAT3 (Figure 1H). Cells from DKO mice had a substantial enhancement in eliminating infection, while the TKO $\mathrm{CD} 4^{+} \mathrm{T}$ cells lacked in vivo antifungal activity compared with the WT CD4 $4^{+} \mathrm{T}$ cells (Figure 1I). RNA sequencing (RNA-seq) of whole lung tissue revealed that $R a g 1^{-1-}$ mice that received DKO CD4 $4^{+} \mathrm{T}$ cells had an upregulation of Stat3-regulated genes, such as Th17 cytokines (Supplemental Figure 1A; supplemental material available online with this article; https://doi.org/10.1172/jci.insight.91894DS1).

Il21R expression in $C D 4^{+} T$ cells is essential for $P$. murina clearance. RNA-seq of whole lung also revealed a defect in $I l 21$ and Csf2 expression in Rag $1^{-/-}$mice that received TKO CD4 ${ }^{+} \mathrm{T}$ cells (Supplemental Figure 1A). We also observed a significant impairment of IL-21 and GM-CSF production, as well as IL-2, MIP3 $\alpha$, CD40L, TGF- $\beta$, IL-17A, and IL-17F, in Th17-differentiated Stat3 ${ }^{--}$CD $4^{+}$T cells (Supplemental Figure 1, $\mathrm{B}-\mathrm{J}$ ). To assess the relevance of IL-21 signaling during $P$. murina infection, we measured fungal burdens in 
A

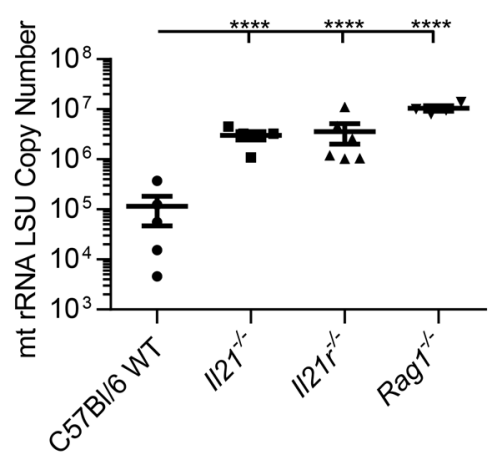

D

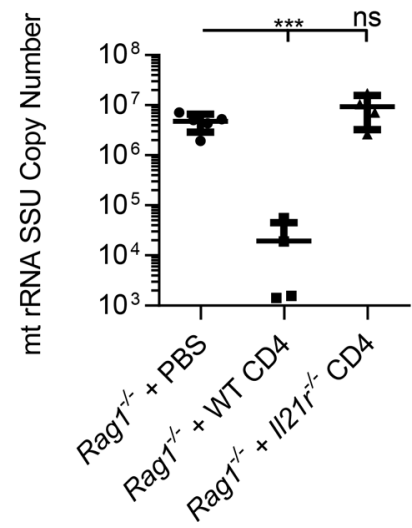

B

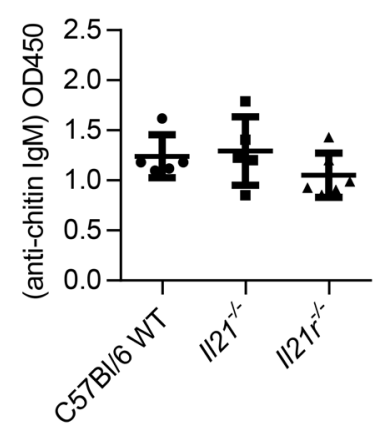

E

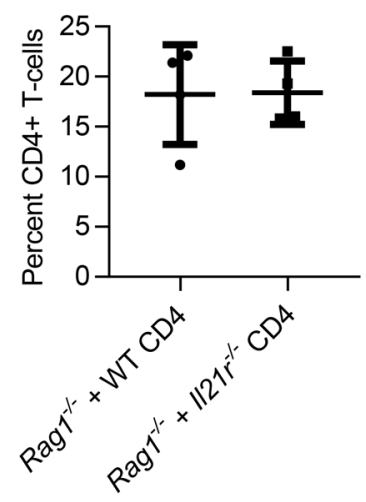

C

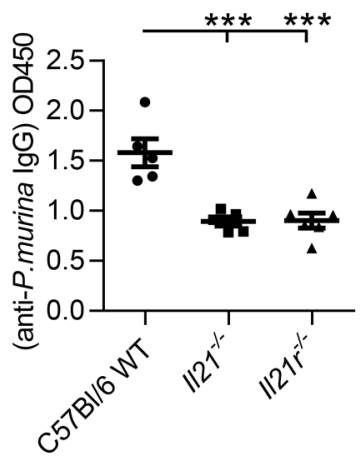

$\mathbf{F}$

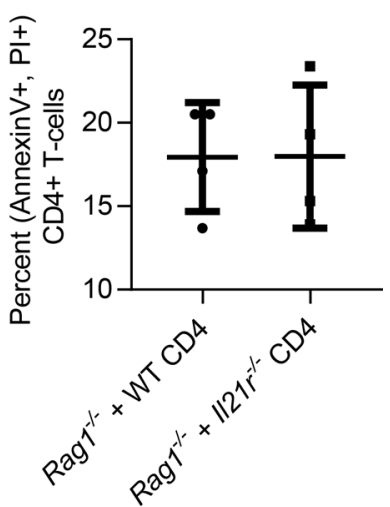

Figure 2. CD4 ${ }^{+}$T cell IL-21 signaling is required for $P$. murina clearance. WT and KO mice were infected for 4 weeks with $2 \times 10^{5} P$. murina asci. (A) Realtime PCR of whole lung RNA for $P$. murina mitochondrial ribosomal RNA large subunit was performed and quantified to assess degree of $P$ neumocystis burden. (B) Chitin-specific IgM antibodies in the serum were measured by direct ELISA against chitin at absorbance OD450. (C) Pneumocystis-specific IgC antibodies were measured by direct ELISA against $P$. murina at absorbance OD450. WT and KO CD4+ $T$ cells were adoptively transferred via i.v. injection to Rag1-/- mice 2 weeks prior to primary infection. (D) Real-time PCR of whole lung RNA for $P$. murina mitochondrial ribosomal RNA large subunit was performed and quantified to assess degree of Pneumocystis burden. Lungs were also digested into a cell suspension and stained with (E) anti-CD3 and anti-CD4 to define CD4+ T cells and $(\mathbf{F})$ annexin $V$ and PI for apoptotic cells. Values are reported as means \pm SEM for $n=4-6$ per group. A-F are representative data of 2 experiments. $P$ values are annotated as follows: ${ }^{* *} P \leq 0.001$, and ${ }^{* * *} P \leq 0.0001$ (1-way ANOVA).

both $I I 21^{-/-}$and $I I 21 r^{\prime-}$ mice after a 4-week infection. Mice deficient in either IL-21 or IL-21R were unable to clear infection (Figure 2A). IL-21- and IL-21R-deficient mice had normal levels of natural IgM antibodies against chitin (Figure 2B). However, consistent with IL-21's known role in regulating B cell activation and class switching, they had reduced class-switched IgG responses to $P$. murina antigen (Figure 2C). To assess if there was a defect in $\mathrm{CD} 4^{+} \mathrm{T}$ cell effector function, we adoptively transferred $\mathrm{CD} 4^{+} \mathrm{T}$ cells from $I 121 r^{--}$or WT mice into Rag $1^{-1-}$ mice. Mice that received $I l 21 r^{--} \mathrm{CD} 4^{+} \mathrm{T}$ cells were incapable of mediating a protective immune response (Figure 2D), despite equivalent homing and viability of $\mathrm{CD}^{+} \mathrm{T}$ cells to the lung (Figure

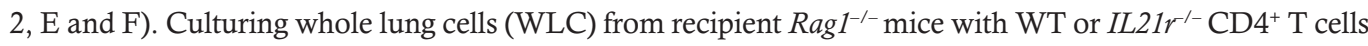
revealed a reduction in many cytokines, including IFN- $\gamma$, IL-5, IL-17a, TNF- $\alpha$, and IL- $1 \beta$, in response to P. murina antigen stimulation, whereas these cells were capable of responding to $\mathrm{CD} 3 / \mathrm{CD} 28$ stimulation (Supplemental Figure 2, A-G). Of note CD3/CD28-stimulated IL-22 was substantially reduced in lung cells from mice that received IL-21 $\mathrm{R}^{--} \mathrm{CD} 4^{+} \mathrm{T}$ cells compared with WT CD4 $4^{+} \mathrm{T}$ cells (Supplemental Figure 2G). Furthermore, in vitro Th17 differentiation of $I l 21 r^{-1} \mathrm{CD} 4^{+} \mathrm{T}$ cells revealed a full log reduction of IL-22 protein production compared with WT cells (Supplemental Figure 2, H-M).

IL-22 signaling mediates reduction in burden in IL-21R-deficient mice. IL-22RA1 is normally expressed in the conducting airway but can be upregulated in the distal epithelium in the setting of influenza infection (44). To assess if this is also the case in P. murina infection, we performed IHC for IL-22RA1 and observed intense staining at the site of infection in the distal lung epithelium (Figure 3A). To test if IL-22 played a role in immunity to $P$. murina infection, we performed a rescue experiment on WT CD4-depleted and $I I 21 r^{-1-}$ mice that had been injected for 2 weeks by i.p. administration of recombinant human IL-22-FC 

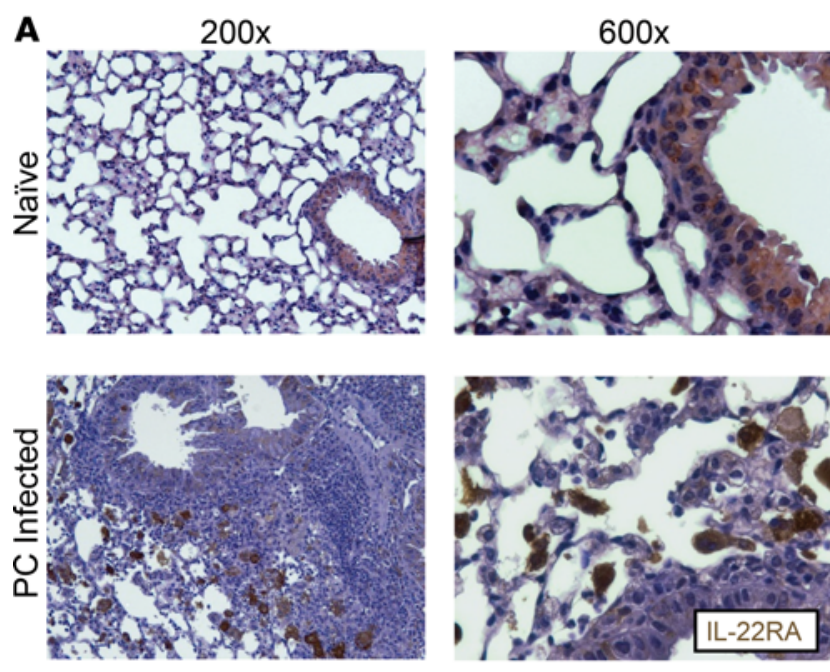

B
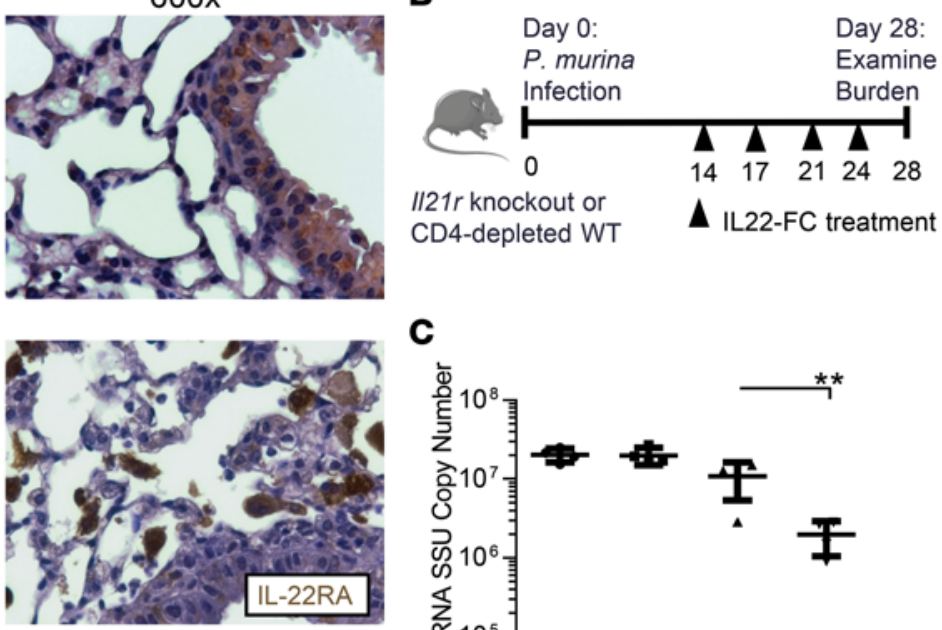

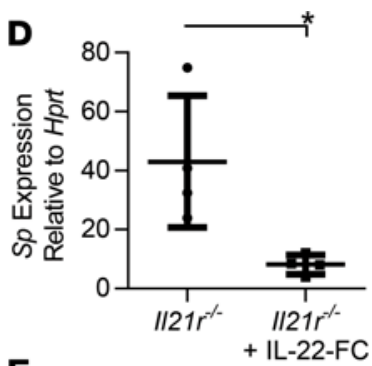

E

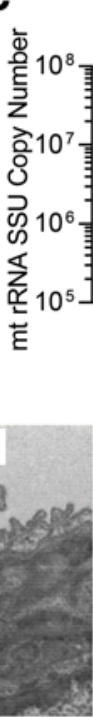

\section{C}

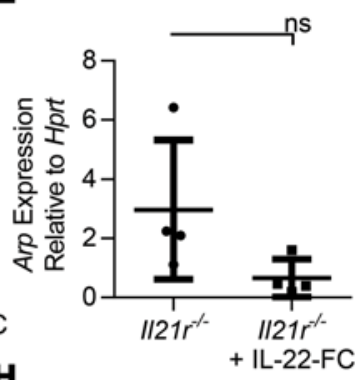

I

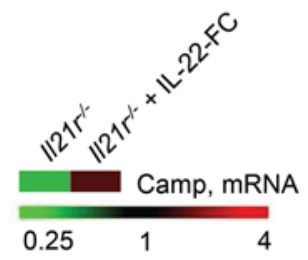

J

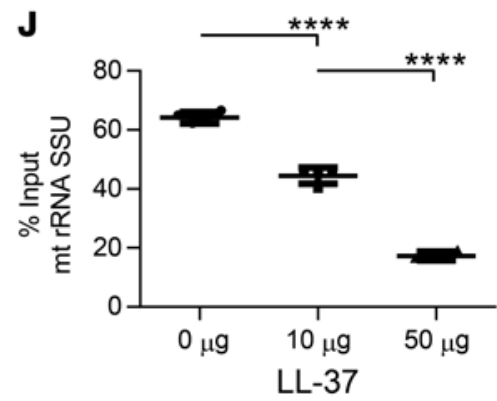

K

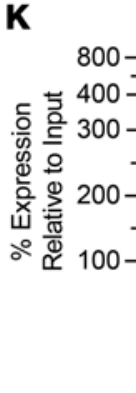

H
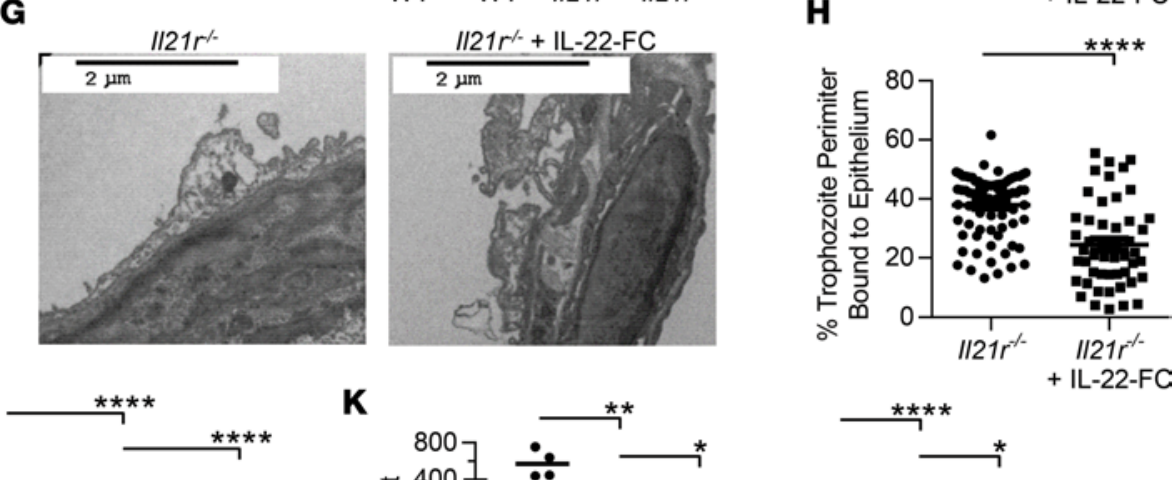

Figure 3. IL-22-FC treatment is protective in II21 ${ }^{/-}$mice. (A) Histology slides of lung tissue from WT naive and $P$. murina-infected mice were stained for IL-22RA by IHC. IL-21R-deficient and CD4-depleted WT mice were infected with $P$. murina for 2 weeks prior to 2 weeks of biweekly treatment of IL-22-FC $(n=4)$. (B) Schematic timeline of IL-22-FC treatment model. Real-time PCR of whole lung RNA for (C) P. murina mitochondrial ribosomal RNA large subunit, (D) Sp, and (E) Arp was performed to assess degree of Pneumocystis burden. (F) Schematic timeline of the short-term IL-22-FC treatment model where IL-21R-deficient mice received a single dose of IL-22-FC at the 2 week mark of infection $(n=3)$. (G) Representative transmission electron microscopy images of pneumocyte/trophozoite interaction. (H) Quantification of percent trophozoite perimeter bound to murine pneumocytes. (I) Whole lung RNA was isolated, sequenced using an Illumina NextSeq 500, and analyzed for differential expression of genes associated with antimicrobial responses $(n=3)$. P. murina was cultured in vitro with 10 or $50 \mu \mathrm{g} / \mathrm{ml}$ concentrations of LL-37 protein. RNA from in vitro incubation with LL-37 was used to perform Real-time PCR on (J) P. murina mitochondrial ribosomal RNA small subunit, (K) Arp, and Sp and normalized to input expression. Values are represented as means $\pm \mathrm{SEM}$. A-E, J, and $\mathbf{K}$ are representative of 2 experiments. G-I were performed once. $P$ values are annotated as follows: ${ }^{*} P \leq 0.05,{ }^{*} P \leq 0.01$, and ${ }^{* * *} P \leq 0.0001$ (1-way ANOVA).

protein (rhIL-22-FC) twice a week for 2 weeks (Figure 3B). Although, hIL-22-FC had no effect on WT CD4-depleted mice, it was able to reduce burden in $I l 21 r^{-1-}$ mice by nearly $90 \%$ (Figure 3C). The reduction in burden was most evident looking at a trophozoite-enriched expression marker serine protease $(S p)$ (Figure 3D). However, ascus-enriched expression marker Arp had no significant change (Figure 3E). We evaluated the effect of a single dose of hIL-22-FC treatment on Il21r-KO mice by multiple assays including RNA-seq of whole lung tissue and transmission electron microscopy (TEM) (Figure 3F). In control mice, we observed tight apposition of the fungal trophozoites and the lung epithelium (Figure $3 \mathrm{G}$ ). In contrast, 
A

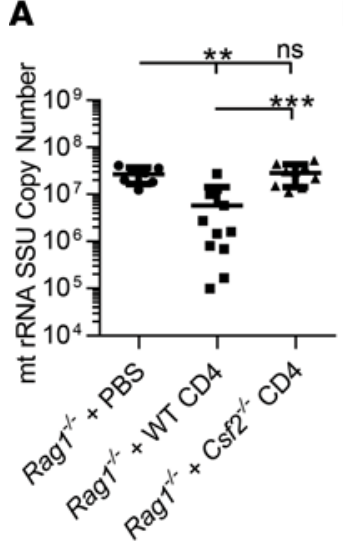

B

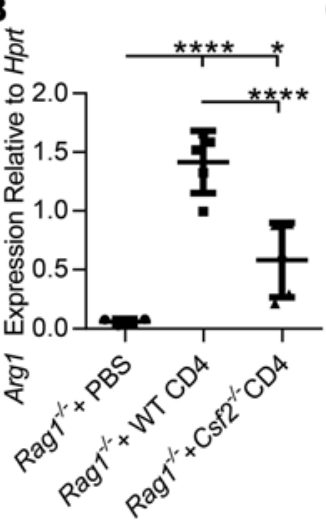

C

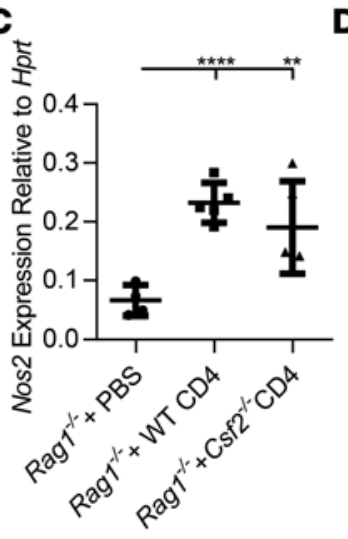

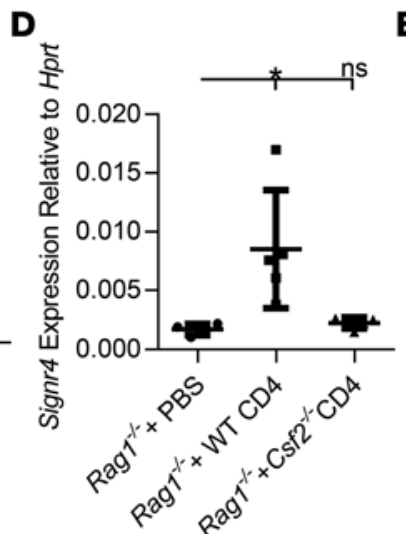
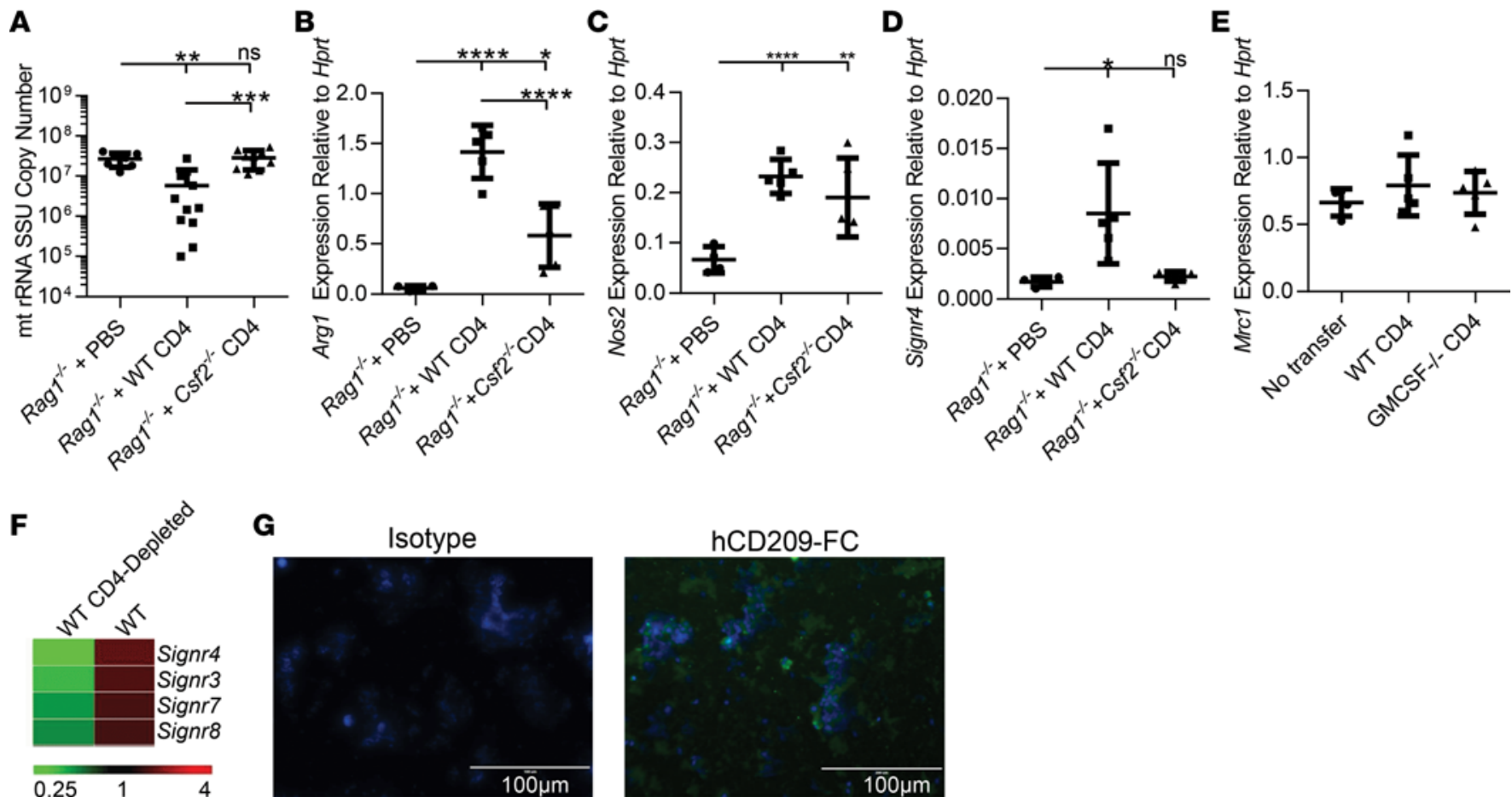

Figure 4. GM-CSF production by CD4 ${ }^{+} T$ cells is required for successful immune response. WT and $C s f 2^{-l_{-}} \mathrm{CD} 4^{+} \mathrm{T}$ cells were adoptively transferred via i.v. injection to Rag1/- mice 2 weeks prior to primary infection. Real-time PCR of whole lung RNA for (A) P. murina mitochondrial ribosomal RNA small subunit was performed to assess degree of $P$. murina burden, as well as on murine expression markers Arg1 (B), Nos2 (C), Signr4 (D), and Mrc1 (E). (F) Whole lung RNA was isolated from WT and WT CD4-depleted mice, which were infected with $P$. murina for 2 weeks. RNA was then sequenced using an Illumina NextSeq 500 and analyzed for differential expression of Signr family members $(n=4)$. (G) Representative images of $P$. murina inoculum incubated directly with human CD209-FC (hlgG4) recombinant protein and stained with DAPI (blue) and anti-hlgG4 (FITC). Values are represented as means \pm SEM. A is a composite of 2 experiments. B-E and $\mathbf{G}$ are representative data of 2 experiments. $\mathbf{F}$ was performed once. $P$ values are annotated as follows: ${ }^{*} P \leq 0.05$, ${ }^{* *} P \leq 0.01,{ }^{* *} P \leq 0.001$, and ${ }^{* * *} P \leq 0.0001$ (1-way ANOVA).

this degree of attachment/apposition was substantially reduced in IL-22-treated $I l 21 r^{-1}$ mice (Figure $3 \mathrm{H}$ ). By RNA-seq, there was a significant increase of cathelicidin antimicrobial peptide (CAMP) in hIL-22-FCtreated mice (Figure 3I). In vitro, CAMP — also known as LL-37 — demonstrated dose-dependent killing of $P$. murina (Figure $3 \mathrm{~J}$ ). This killing was also measured by a dose-dependent decrease in transcript of the life form-specific markers Arp and Sp (Figure 3K). We also investigated if IL-22 could reduce trophic burden in the adoptive transfer model by using IL-22-FC to treat mice that received WT or Il21r $\mathrm{r}^{-1-} \mathrm{CD} 4^{+} \mathrm{T}$ cells. Again IL-22-FC treatment reduced trophic $(S p)$ burdens in the lung (Supplemental Figure 3). These data show that IL-22 is sufficient to reduce burden in I121 $\mathrm{r}^{-1-}$ mice, but in order to determine if IL-22 pro-

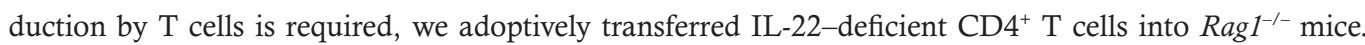
IL-22-deficient $\mathrm{CD}^{+} \mathrm{T}$ cells remained capable of mediating reduction in fungal burden equivalent to the WT controls (Supplemental Figure 4A). Interestingly, this reduction in burden was correlated with an upregulation in type II cytokines IL-5 and IL-13 (Supplemental Figure 4, B and C).

$C D 4^{+} T$ cell CSf2 is required for successful fungal clearance. To determine whether other STAT3-regulated factors, such as GM-CSF, may also be required for $P$. murina clearance, we adoptively transferred WT or $C s f 2^{-1-}$ $\mathrm{CD}^{+} \mathrm{T}$ cells into $\mathrm{Rag} 1^{1^{--}}$mice. $R a g 1^{-/-}$mice that received $C s f 2^{---} \mathrm{CD} 4^{+} \mathrm{T}$ cells were not capable of generating

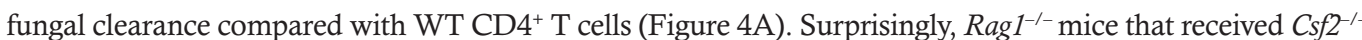
$\mathrm{CD}^{+} \mathrm{T}$ cells showed no significant difference in total cell recruitment to the lung (Supplemental Figure $5 \mathrm{~A}$ ). This included no significant differences in the percentage or total number of CD4 ${ }^{+} \mathrm{T}$ cells or macrophages (Supplemental Figure 5, B-E). Although there was no difference in macrophage recruitment, we did observe a decrease in expression of Arg1 (Figure 4B), while Nos2 was unaffected (Figure 4C). We also measured the relative expression of the mannan receptors $C d 209 e$ and $M r c 1$, observing an absence specifically in expression of Cd209e (Signr4) in mice that received Csf2 $2^{-/-} \mathrm{CD} 4^{+} \mathrm{T}$ cells (Figure 4, D and E). We conducted analysis of a previous RNA-seq dataset of WT control and CD4-depleted mice after 2 weeks of infection, and we observed 
A

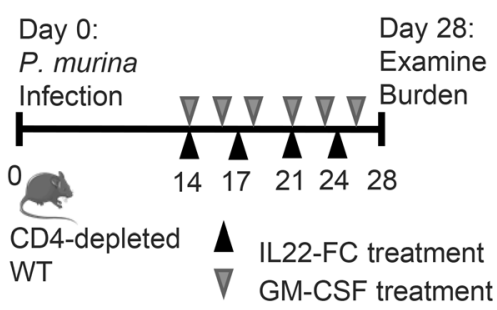

B

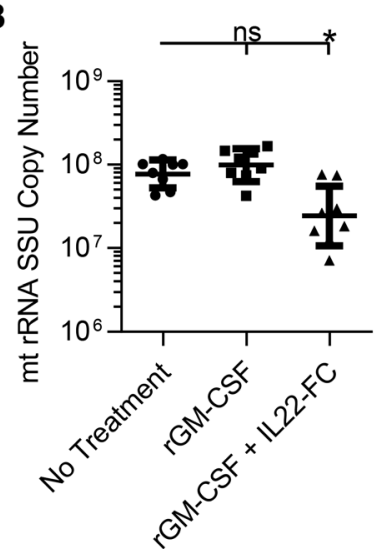

C

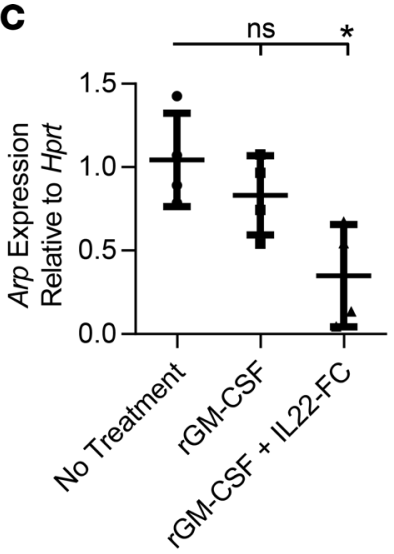

D

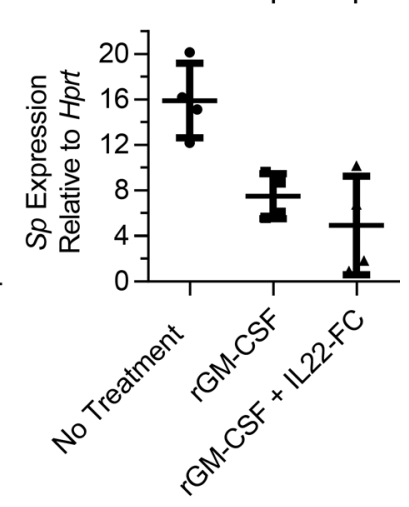

Figure 5. Combinatorial IL-22 and GM-CSF treatment is protective in CD4-depleted mice. CD4-depleted WT mice were infected with $P$. murina for 2 weeks prior to 2 weeks of biweekly treatment of IL-22-FC and triweekly administration of recombinant GM-CSF ( $n=4)$. (A) Schematic timeline of IL-22-FC and GM-CSF combinatorial treatment model. Real-time PCR of whole lung RNA for (B) P. murina mitochondrial ribosomal RNA small subunit, (C) Arp, and (D) Sp was performed to assess degree of $P$. murina burden. $P$ values are annotated as follows: ${ }^{*} P \leq 0.05$ and ${ }^{* *} P \leq 0.01$ (1-way ANOVA).

a decrease in several of the CD209 family, including Cd209e (Signr4), Cd209d (Signr3), Cd209g (Signr7), and Cd209f (Signr8) (Figure 4F). To determine if CD209 is a pattern-recognition molecule for P. murina, we assessed the binding ability of rhCD209-FC on lung homogenate of a $P$. murina-infected mouse, and we were able to visually confirm binding of hCD209 to the fungus (Figure 4G).

Combinatorial treatment with GM-CSF and IL-22 significantly reduces Pneumocystis burden. To assess a potential combinatorial effect of IL-22 and GM-CSF during Pneumocystis infection, CD4-depleted WT mice were infected for 2 weeks, followed by treatment for 2 weeks with 3 doses of GM-CSF per week, with or without 2-doses of hIL-22-FC per week (Figure 5A). GM-CSF alone, similar to IL-22 alone, had no effect on $P$. murina burden; however, the combination of GM-CSF and hIL-22-FC had an approximately half-log reduction in burden (Figure 5B). The trophic-dominant expression marker $S p$ was decreased by GM-CSF alone, while the addition of IL-22 did not appear to provide any additional reduction (Figure 5D). Alternatively, GM-CSF alone did not have a significant decrease on the ascus-dominant expression marker Arp, while the combination of GM-CSF and IL-22 did have a decrease (Figure 5C).

\section{Discussion}

We began this research focused on discerning which $\mathrm{CD}^{+} \mathrm{T}$ cell responses and factors are required and/ or sufficient for mediating the clearance of $P$. murina infection. We tested a number of effector cytokine and cytokine receptor-KO mice that represented deficiencies in the 3 dominant effector Th cell subsets, Th1, Th2, and Th17. We found that IL-12, IL-4, IL-23, and IL-17 signaling were all dispensable for successfully clearing infection. This led us to take a broader approach of examining the roles of the STATs that regulate differentiation and function for each of the Th cell subsets: STAT4 for Th1, STAT6 for Th2, and STAT3 for Th17. We found that both STAT4 and STAT6 were expendable during infection, while STAT3 was crucial. To assess the possibility that STAT4 and STAT6 play complementary roles, we also examined the competence of Stat4/Stat6-DKO mice. Clearance of P. murina infection by DKO mice further validates that neither is required for clearance. This susceptibility of mice deficient in Stat 3 is consistent with prior reports of $P$. jiroveci infection in patients with human hyper IgE syndrome (HIES), a rare primary immunodeficiency associated with a STAT3-dominant negative mutations $(45,46)$.

It is difficult to associate phenotypes observed in the primary infection model with a specific intrinsic defect of the $\mathrm{CD}^{+} \mathrm{T}$ cells since $\mathrm{T}$ cells can orchestrate multiple distinct modes that mediate clearance, including the activation of humoral responses. Therefore, we moved to utilization of an adoptive transfer

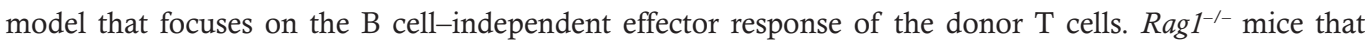
received $\mathrm{CD}_{4}^{+} \mathrm{T}$ cells from Stat4 ${ }^{-/-}$and Stat $^{-{ }^{--}}$mice were able to control infection; however, cells from Stat $3^{-1-}$ CD4-Cre mice were not capable of fungal clearance. This demonstrates that an intrinsic STAT3-dependent effector function in $\mathrm{CD} 4^{+} \mathrm{T}$ cells is required to mount a successful immune response. To reiterate our finding in the primary infection model that Th17 cells are not required, adoptively transferred Rorc $^{-1}$ 
$\mathrm{CD}^{+} \mathrm{T}$ cells cleared infection. Interestingly, Stat4/Stat6 DKO CD4 ${ }^{+} \mathrm{T}$ cells had enhanced clearance, which we are able to associate with an upregulation of Stat 3 signaling within these cells. This was determined by RNA-seq data that showed an increase in Stat3-regulated genes such as $I l 23 r, I l 17 a$, and Il22. Additionally, conditional deletion of STAT3 in the DKO CD4 ${ }^{+} \mathrm{T}$ cells completely abrogated their ability to mediate fungal clearance upon adoptive transfer of these TKO CD4 ${ }^{+} \mathrm{T}$ cells. Rorc has been directly implicated in regulation of IL-17A and IL-22 expression during infection, but the adoptive transfer data suggest that Rorc is dispensable for fungal clearance in this model. We hypothesize that type II cytokines and other effector molecules may be mediating this effect, and future studies will need to compare the antigen-specific responses comparing Rorc $^{-1-} \mathrm{CD} 4^{+} \mathrm{T}$ cells with Stat $^{3^{-1-}} \mathrm{CD} 4^{+} \mathrm{T}$ cells.

The RNA-seq dataset, in conjunction with in vitro $\mathrm{T}$ cell differentiation data, pointed at several potential downstream STAT3-dependent factors that may be involved in $\mathrm{CD}^{+} \mathrm{T}$ cell-mediated immunity, including IL-21R and GM-CSF. With recent studies showing a multifunctional role in IL-21 signaling, we proceeded to examine the potential prerequisite of IL-21 during P. murina infection. Both $I l 21^{-{ }^{--}}$and $I l 21 r^{-1-}$ mice were susceptible to $P$. murina infection. In conjunction with our studies, case reports on patients with an $I L 21 R$ (loss-of-function) mutation-associated primary immunodeficiency were found to be susceptible to $P$. jirovecii infection (41). The primary infection murine models of $I l 21^{-/-}$and $I l 21 r^{-1}$ mice recapitulate the human phenotype of susceptibility. $I l 21 r^{-1-}$ mice have a defect in generating class-switched antibodies, as well as a T cell-intrinsic defect, which we demonstrated through the adoptive transfer model. Under CD3/CD28 stimulation, $I 21 r^{-1-} \mathrm{CD}^{+} \mathrm{T}$ cells had demonstrated a significant defect in the production of IL-22 and IL-17. Similarly, CD4 ${ }^{+} \mathrm{T}$ cells from humans with $I L 21 R$ loss-of-function mutations also displayed a defect in IL-22 production. The pathway for IL-21 regulation of $I l 22$ expression has been recently revealed to be mediated by STAT3 activation, which directed our interest in exploring the potential role of IL-22 during Pneumocystis spp. infection $(41,47,48)$.

In naive mice, IL-22R expression is primarily only detectable in the large airways of lung; however, it has been shown to be upregulated on epithelial cells in response to tissue damage and infection (44, 49). We demonstrate that IL-22RA1 is upregulated in the alveolar epithelium in response to $P$. murina infection, suggesting that it may indeed play a role in generating a successful immune response. We were able to confirm its functionality during infection by rescuing $I l 21 r^{-1}$ mice with a short regimen of rhIL-22-FC. Using real-time PCR of transcripts that are expressed in specific life forms of $P$. murina, we showed that this effect of IL-22 was selective for the trophic form in both $I 121 r^{--}$mouse models, as well as in the adoptive transfer model. As the troph attaches to alveolar type I cells, we showed through TEM that hIL-22-FC treatment had a significant effect on the trophic form's ability to adhere to alveolar epithelial cells. However, it was unclear if this difference in host-pathogen binding was due to modifications of the epithelial barrier or a decrease in the overall health of trophic forms. We performed RNA-seq on IL-22-treated $I 121 r^{-1}$ lung tissue to shed light on the possible pathways IL-22 treatment was influencing and, surprisingly, found that IL-22 upregulated Camp in Il21 $1 r^{-1}$ mice. Recombinant human CAMP, LL-37, had a dose-dependent fungicidal activity against $P$. murina in vitro. We found this particularly interesting and are currently developing an in vivo model to test CAMP as a potential therapy in Pneumocystis-infected mice. However, IL-22-FC treatment had no effect on CD4-depleted WT mice, demonstrating that, although IL-22 may play a role in mediating an immune response to Pneumocystis, it is not sufficient.

As IL-22 treatment alone was not sufficient to rescue CD4-depleted mice, we explored other possible cytokines and chemokine that are both absent in Stat3-KO mice and present in Il21r-KO mice. GM-CSF has previously been associated with Pneumocystis spp. infection, but therapeutic treatment with GM-CSF has had inconsistent results. Thus, we confirmed with our adoptive transfer model that GM-CSF production, specifically by $\mathrm{CD}^{+} \mathrm{T}$ cells, is required to mount optimal fungal clearance. Although macrophage numbers in BAL fluid were equivalent in mice that received WT CD4 $4^{+} \mathrm{T}$ cells, there was a decrease in arginase expression and complete loss of the mannan receptor, CD209e expression. We demonstrated that CD209e is capable of directly binding the ascus and trophic form of $P$. murina, and we are currently examining the importance of this molecule in the host-pathogen interaction. Finally, to test whether GM-CSF and IL-22 functioned in conjunction, we treated CD4-depleted WT mice with both rGM-CSF and hIL-22-FC, and only mice that received a combination of both had a reduction in burden. These data suggest that combination therapy may be ideal for lymphopenic hosts. It is important to mention that these experiments may be limited in efficacy by the short half-life of GM-CSF in vivo. 
The precise role of $\mathrm{CD}^{+} \mathrm{T}$ cells during $P$. murina infection appears to be outside the standard categories we use to classify $\mathrm{CD}^{+} \mathrm{T}$ cell effector functions. There may in fact be a much more unique and complex set of signals to mediate a variety of modes of clearance. Importantly, many of the known genetic syndromes associated with primary immunodeficiency and $P$. jiroveci infection in humans can be recapitulated in the murine model of infection. These in vivo models have been critical in identifying the complex IL-21-, STAT3-, IL-22-, and GM-CSF-dependent pathway of $\mathrm{CD}^{+} \mathrm{T}$ cell clearance capable of providing protection against Pneumocystis spp. While the downstream mechanism and pathways have yet to be fully elucidated regarding these factors, identifying IL-22 and GM-CSF as protective cytokines may represent the first step in developing effective, targeted immune-based forms of treatment.

\section{Methods}

Mice. WT C57BL/6J, WTBALB/cJ, Rag1-/-(B6.129S7-Rag1 1mIMom/J), Stat6 ${ }^{-1-}\left(B 6.129 S 2[C]-S t a t 6^{\text {tmlGru }} / J\right)$, Il21r $^{-1}$

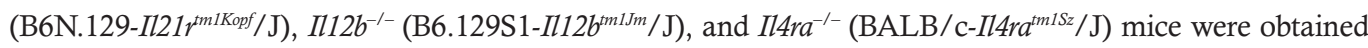

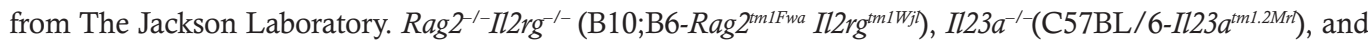

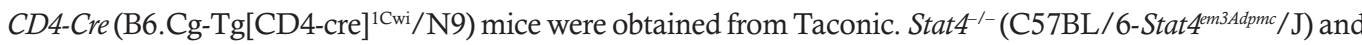
Stat $^{\text {fl/fl }}\left(\right.$ B6.129S1-Stat $3^{\text {tmlXyfu } / J) ~ m i c e ~ w e r e ~ o b t a i n e d ~ f r o m ~ M . H . ~ K a p l a n ~(I n d i a n a ~ U n i v e r s i t y ~ S c h o o l ~ o f ~ M e d i-~}$

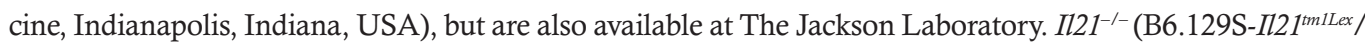
Mmucd) mice were provided by S. Khader (Washington University in St. Louis, St. Louis, Missouri, USA), and $C_{S} 2_{2^{--}}\left(\mathrm{B} 6.129 \mathrm{~S}-C_{S} f 2^{t m I M I g} / \mathrm{J}\right)$ splenocytes were received from Z.C. Chroneos (Pennsylvania State University College of Medicine, Hershey, Pennsylvania, USA). $1 l 17 \mathrm{ra}^{-/-}(\mathrm{C} 57 \mathrm{BL} / 6-1 / 17 \mathrm{ra}$ tmlKoll $/ \mathrm{J})$ were previously generated and maintained by Jay K. Kolls. All mice were historically backcrossed 8-12 generations and bred in specific pathogen-free rooms within animal facilities at the University of Pittsburgh. We crossed Stat $3^{\text {f/fl }}$

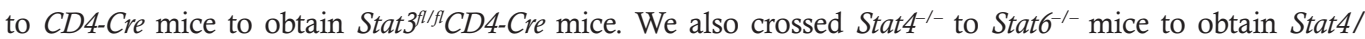
Stat6-DKO mice, which then were additionally crossed to Stat $3^{f / f} \mathrm{CD} 4$-Cre mice to obtain Stat4/Stat6/Stat3/ CD4-Cre-conditionally TKO mice.

$P$. murina inoculum preparation and administration, $C D 4^{+} T$ cell depletion, and in vivo recombinant protein treatment. P. murina is propagated and passaged in Rag2/Il2gc-DKO mice. Whole lung of an infected mouse, stored at $-80^{\circ} \mathrm{C}$ in $\mathrm{PBS}$, is thawed and strained through a $70-\mu \mathrm{m}$ filter. Lung suspension is then centrifuged and resuspended to a concentration of $2 \times 10^{6}$ cysts $/ \mathrm{ml}$. Cyst counts are determined microscopically, as previously described (50). Mice are infected with $100 \mu 1$ of inoculum prep $\left(2 \times 10^{5} \mathrm{cysts}\right)$ via oral pharyngeal administration as previously described $(22,50,51)$. CD4-depleted mice were given $300 \mu \mathrm{g}$ GK1.5 (antiCD4 monoclonal antibody [GK1.5]; produced in house) weekly, starting 48 hours prior to infection. Mice were infected with Pneumocystis for 2, 4, or 6 weeks. Treatment with recombinant proteins would begin at the 2-week time point. Mice received either $4 \mu \mathrm{g}$ hrIL-22-FC (Generon Corporation) or $4 \mu \mathrm{g}$ recombinant GM-CSF (Shenandoah Biotechnology, 200-15). Mice were treated either once and assayed 72 hours after treatment, or they were treated twice a week for 2 weeks.

$R N A$ isolation, real-time PCR assay, and P. murina mtRNA copy number quantification. The right middle lobe was harvested in $1 \mathrm{ml}$ of TRIzol Reagent (Thermo Fisher Scientific, 15596026) and homogenized by Bio-Gen PRO200 Homogenizer (PRO Scientific, 01-01200). RNA was purified in accordance to the TRIzol Reagent manufacturer's protocol. The iScript cDNA Synthesis Kit (Bio-Rad, 1708891) was used to synthesize cDNA from $1 \mu \mathrm{g}$ of total RNA per $20 \mu \mathrm{l}$ reaction. Real-time PCR was performed by either SsoAdvanced Universal Probes Supermix (Bio-Rad, 1725281) or iTaq Universal SYBR Green Supermix (Bio-Rad, 1725121) with 5\% of the cDNA reaction. RNA copy number standards and primers for $P$. murina mitochondrial large subunit (mtLSU) and small subunit (mtSSU) ribosomal RNA were generated as previously described $(22,52)$.

In vitro cathelicidin antimicrobial peptide killing assay. Prepared Pneumocystis inoculum was plated in 96-well plates at $2 \times 10^{5}$ per $100 \mu 1$ per well. Wells were then spiked with $25 \mu 1$ of $5 \times$ desired LL-37 concentration and incubated overnight (16 hours). Distilled, deionized $\mathrm{H}_{2} \mathrm{O}(125 \mu \mathrm{l})$ were added to the well and were then transferred to $750 \mu 1$ of TRIzol Reagent (Thermo Fisher Scientific, 15596026). RNA isolation was performed in accordance to the TRIzol Reagent Manufacturer's protocol, and RNA pellet was resuspended in $30 \mu \mathrm{l}$ of nuclease-free $\mathrm{H}_{2} \mathrm{O}$. Solubilized RNA (5 $\left.\mu 1\right)$ was used in iScript reaction, and copy number was determined as described above.

Total and naive $C D 4^{+} T$ cell purification, $T$ cell differentiation, and adoptive transfer. Murine strain-specific spleens were harvested and directly strained through $70-\mu \mathrm{M}$ filters and suspended at a concentration of $1 \times 10^{8}$ cells per milliliter. EasySep Mouse CD4 ${ }^{+} \mathrm{T}$ Cell Isolation Kit (Stemcell Technologies, 19852) 
and Mouse Naive CD4 ${ }^{+}$T Cell Isolation Kit (Stemcell Technologies, 19765) were used to purify total splenic $\mathrm{CD}^{+} \mathrm{T}$ cells for adoptive transfer and naive $\mathrm{CD}^{+} \mathrm{T}$ cells for in vitro $\mathrm{T}$ cell differentiation, respectively. For $\mathrm{T}$ cell differentiation, $1 \times 10^{5}$ naive $\mathrm{CD} 4^{+} \mathrm{T}$ cells in $200 \mu \mathrm{l}$ supplemented IMDM media (Gibco, 11140-050) were plated on anti-CD3/anti-CD28-treated 96-well cell culture plates. Components of supplemented IMDM media for T cell lineage-specific differentiations are as follows: Th1 included IL-2, IL-12, and anti-IL-4; Th2 included IL-2, IL-4, anti-IFN- $\gamma$; and Th17 included IL-23, TGF- $\beta$, IL-6, IL-1 $\beta$, anti-IL-4, anti-IFN- $\gamma$. Under these conditions, $\mathrm{CD} 4^{+} \mathrm{T}$ cells were cultured for 5 days at $37^{\circ} \mathrm{C}$, with a repletion of stimulants at day 4 . Supernatants from each differentiation condition were measured for cytokine concentration using Milliplex (MilliporeSigma, MCYTMAG-70K-PX32). Mouse IL-22 was measured by ELISA (BioLegend, 436304) following the manufacturer's instructions.

Antigen-specific immunoglobulin assay. Nunc MaxiSorp flat-bottom 96-well plates (eBioscience, 44-240421) were coated with $100 \mathrm{ng}$ target antigen in $100 \mu \mathrm{l}$ bicarbonate coating buffer and blocked with $5 \%$ milk in PBS. Plates were incubated with dilute serum (typically 1:64), followed by an FC-specific, HRP-conjugated secondary antibody from eBioscience. Plates are then developed with TMB Substrate Reagent Set (BD Bioscience, 555214), neutralized with $\mathrm{H}_{2} \mathrm{SO}_{4}$, and assayed for absorbance at OD450.

RNA-seq. Total whole lung tissue RNA was used to perform RNA-seq. RNA quantity and quality was assessed using Qubit 2.0 fluorometer and Agilent Bioanalyzer TapeStation 2200. Illumina TruSeq Stranded mRNA sample prep kit was used for library preparation, followed by validation with KAPA Biosystems primer premix kit with Illumina-compatible DNA primers and Qubit 2.0 fluorometer, as previously described (52). The cDNA libraries were pooled at a final concentration $1.8 \mathrm{pM}$. Cluster generation and 75-bp paired-read single-indexed sequencing was performed on Illumina NextSeq 500's. Raw reads were processed and mapped; then, gene expression measurements and nucleotide variation were evaluated by previously described methods (52). Data was deposited in the Sequence Read Archive BioProject, number SRP145318.

WLC preparation, antigen stimulation, and flow cytometry. The right inferior lobe was diced with scissors, followed by 90 -minute digestions in collagenase/DNase (MilliporeSigma) solution at $37^{\circ} \mathrm{C}$. Cells were then filtered through a $70-\mu \mathrm{m}$ strainer, red blood cell lysed, and resuspended in PBS. Viable cells were quantified with trypan blue and used in downstream assays. For antigen stimulation, WLC were plated in 96-well tissue culture plates at $1 \times 10^{5}$ per well, in $100 \mu 1$ complete IMDM supplemented with IL-2 and 100 ng $P$. murina antigen. After 72 hours, supernatants were assayed for cytokines, and cells were assayed for gene expression by RNA isolation and RT-PCR assay. WLCs were also prepared for flow cytometry as follows: $1 \times 10^{6}$ cells were resuspended in $50 \mu 12 \%$ FBS in PBS supplemented with $0.4 \mu \mathrm{g}$ anti-CD16/CD32 (eBioscience, clone 93). After a 15 -minute incubation at $4^{\circ} \mathrm{C}, 50 \mu 1$ of $2 \times$ antibody cocktail was added to cells for 1 hour at $4^{\circ} \mathrm{C}$. Antibodies used are as follows: SiglecF-PE (BD Pharmigen, clone E50-2440), CD11b-APC (BioLegend, clone:M1/70), GR1-PE-Cy7 (BD Pharmigen, clone RB6-8C5), CD11c-FITC (eBioscience, clone N418), F4/80-APC-e780 (eBioscience, clone BM8), CD4-APC (eBioscience, clone RM4-5), and CD3-e450 (eBioscience, clone 17A2). BD Annexin V FITC Assay with propidium iodide was also used.

Tissue fixation and microscopy. For IHC, the left lung was inflated with and submerged in 10\% formalin. The tissue was then processed for paraffin embedding and slide sectioning by the Children's Hospital of Pittsburgh Histology Core. The tissue slide was then deparaffinized, rehydrated, and unmasked followed by IL-22RA1 staining as previously described (44). For electron microscopy, the left lung was inflated and submerged in $2.5 \%$ glutaraldehyde. The tissue was then processed and imaged by the Center for Biological Imaging at the University of Pittsburgh. All sections were completely scanned and imaged for $P$. murina trophozoite life forms. The total perimeter of each trophozoite bound to lung epithelial cells was traced, and the percent of the perimeter bound to the lung epithelial cell was quantified.

Statistics. Graphs were generated and statistical significances were analyzed using GraphPad Prism software. $P$ values of pairwise comparisons between groups of 2 were performed by simple 2-tailed unpaired Student's $t$ test, while groups of 3 or more used 1-way ANOVA with Tukey's multiple comparisons. Values are represented as means \pm SEM. $P$ values are annotated as follows ${ }^{*} P \leq 0.05,{ }^{* *} P \leq 0.01$, $* * * P \leq 0.001$, and $* * * * P \leq 0.0001$.

Study approval. All animal studies were approved by the IACUC of the University of Pittsburgh, protocol numbers 1108490, 14084327, and 14084492. All invasive procedures were performed under isoflurane or ketamine/xylazine anesthesia to ameliorate animal distress. 


\section{Author contributions}

WE, MZ, TE, GD, GTN, PC, MP, JFA, KC, and JKK designed and conducted the experiments and manuscript writing. $\mathrm{HC}$ and $\mathrm{KK}$ assisted in generating mutant animals and genotyping. WH assisted with RNAseq. RLG provided reagents and reviewed the paper. JF assisted with the electron microscopy studies, and DP assisted with pathology and IHC.

\section{Acknowledgments}

This research was supported by the Louisiana Board of Regents Endowed Chairs for Eminent Scholars program, as well as by PHS grants R01HL062052, R01AI120033, and R35HL139930.

Address correspondence to: Jay K. Kolls, JBJ 375, 333 S. Liberty St. New Orleans, Louisiana 70112, USA. Phone: 504.988.0456; Email: jkolls1@tulane.edu.

1. Moore RJ, Stanley D. Experimental design considerations in microbiota/inflammation studies. Clin Transl Immunology. 2016;5(7):e92.

2. Knight KL. Study/experimental/research design: much more than statistics. J Athl Train. 2010;45(1):98-100.

3. Committee on Applied and Theoretical Statistics, Board on Mathematical Sciences and Their Applications, Division on Engineering and Physical Sciences, National Academies of Sciences, Engineering, and Medicine. Statistical Challenges in Assessing and Fostering the Reproducibility of Scientific Results: Summary of a Workshop. National Center for Biotechnology Information. https:// www.ncbi.nlm.nih.gov/books/NBK350352/. AccessedMay 21, 2018.

4. Collins FS, Tabak LA. Policy: NIH plans to enhance reproducibility. Nature. 2014;505(7485):612-613.

5. Justice MJ, Dhillon P. Using the mouse to model human disease: increasing validity and reproducibility. Dis Model Mech. 2016;9(2):101-103.

6. Kilkenny C, Browne WJ, Cuthill IC, Emerson M, Altman DG. Improving bioscience research reporting: the ARRIVE guidelines for reporting animal research. PLoS Biol. 2010;8(6):e1000412.

7. Beura LK, et al. Normalizing the environment recapitulates adult human immune traits in laboratory mice. Nature. 2016;532(7600):512-516.

8. Seok J, et al. Genomic responses in mouse models poorly mimic human inflammatory diseases. Proc Natl Acad Sci USA. 2013;110(9):3507-3512.

9. Antiretroviral Therapy Cohort Collaboration (ART-CC), et al. Variable impact on mortality of AIDS-defining events diagnosed during combination antiretroviral therapy: not all AIDS-defining conditions are created equal. Clin Infect Dis. 2009;48(8):1138-1151

10. Huang L, et al. HIV-associated Pneumocystis pneumonia. Proc Am Thorac Soc. 2011;8(3):294-300.

11. Mikaelsson L, Jacobsson G, Andersson R. Pneumocystis pneumonia--a retrospective study 1991-2001 in Gothenburg, Sweden. J Infect. 2006;53(4):260-265.

12. Morris A, et al. Current epidemiology of Pneumocystis pneumonia. Emerging Infect Dis. 2004;10(10):1713-1720.

13. Tansuphasawadikul S, et al. Clinical features, etiology and short term outcomes of interstitial pneumonitis in HIV/AIDS patients. Southeast Asian J Trop Med Public Health. 2005;36(6):1469-1478.

14. Eddens T, Kolls JK. Pathological and protective immunity to Pneumocystis infection. Semin Immunopathol. 2015;37(2):153-162. 15. Kelly MN, Shellito JE. Current understanding of Pneumocystis immunology. Future Microbiol. 2010;5(1):43-65.

16. Casper JT, Ash RA, Kirchner P, Hunter JB, Havens PL, Chusid MJ. Successful treatment with an unrelated-donor bone marrow transplant in an HLA-deficient patient with severe combined immune deficiency ("bare lymphocyte syndrome"). J Pediatr. 1990;116(2):262-265.

17. Centers for Disease Control Prevention (CDC). Pneumocystis pneumonia--Los Angeles. 1981. MMWR Morb Mortal Wkly Rep. 1996;45(34):729-733.

18. Colford JM, Segal M, Tabnak F, Chen M, Sun R, Tager I. Temporal trends and factors associated with survival after Pneumocystis carinii pneumonia in California, 1983-1992. Am J Epidemiol. 1997;146(2):115-127.

19. Elsegeiny W, Eddens T, Chen K, Kolls JK. Anti-CD20 antibody therapy and susceptibility to Pneumocystis pneumonia. Infect Immun. 2015;83(5):2043-2052.

20. Walzer PD, Evans HE, Copas AJ, Edwards SG, Grant AD, Miller RF. Early predictors of mortality from Pneumocystis jirovecii pneumonia in HIV-infected patients: 1985-2006. Clin Infect Dis. 2008;46(4):625-633.

21. Kelly MN, Zheng M, Ruan S, Kolls J, D'Souza A, Shellito JE. Memory CD4+ T cells are required for optimal NK cell effector functions against the opportunistic fungal pathogen Pneumocystis murina. J Immunol. 2013;190(1):285-295.

22. Ricks DM, Chen K, Zheng M, Steele C, Kolls JK. Dectin immunoadhesins and pneumocystis pneumonia. Infect Immun. 2013;81(9):3451-3462.

23. Lund FE, Hollifield M, Schuer K, Lines JL, Randall TD, Garvy BA. B cells are required for generation of protective effector and memory CD4 cells in response to Pneumocystis lung infection. J Immunol. 2006;176(10):6147-6154.

24. Searles S, Gauss K, Wilkison M, Hoyt TR, Dobrinen E, Meissner N. Modulation of inflammasome-mediated pulmonary immune activation by type I IFNs protects bone marrow homeostasis during systemic responses to Pneumocystis lung infection. J Immunol. 2013;191(7):3884-3895.

25. Deckman JM, et al. Pneumocystis infection alters the activation state of pulmonary macrophages. Immunobiology. 2017;222(2):188-197.

26. Perez-Nazario N, Rangel-Moreno J, O'Reilly MA, Pasparakis M, Gigliotti F, Wright TW. Selective ablation of lung epithelial IKK2 impairs pulmonary Th17 responses and delays the clearance of Pneumocystis. J Immunol. 2013;191(9):4720-4730. 
27. Curtis MM, et al. Fidelity of pathogen-specific CD4+ T cells to the Th1 lineage is controlled by exogenous cytokines, interferon-gamma expression, and pathogen lifestyle. Cell Host Microbe. 2010;8(2):163-173.

28. Ma CS, et al. Unique and shared signaling pathways cooperate to regulate the differentiation of human CD4+ T cells into distinct effector subsets. J Exp Med. 2016;213(8):1589-1608.

29. Vogelzang A, McGuire HM, Yu D, Sprent J, Mackay CR, King C. A fundamental role for interleukin-21 in the generation of T follicular helper cells. Immunity. 2008;29(1):127-137.

30. Rao A, Avni O. Molecular aspects of T-cell differentiation. Br Med Bull. 2000;56(4):969-984.

31. Zhu J, Paul WE. CD4 T cells: fates, functions, and faults. Blood. 2008;112(5):1557-1569.

32. Curtis MM, Way SS. Interleukin-17 in host defence against bacterial, mycobacterial and fungal pathogens. Immunology. 2009;126(2):177-185.

33. Linterman MA, et al. IL-21 acts directly on B cells to regulate Bcl-6 expression and germinal center responses. $J$ Exp Med. 2010;207(2):353-363.

34. Zotos D, et al. IL-21 regulates germinal center B cell differentiation and proliferation through a B cell-intrinsic mechanism. $J$ Exp Med. 2010;207(2):365-378

35. Silver JS, Hunter CA. With a little help from their friends: interleukin-21, T cells, and B cells. Immunity. 2008;29(1):7-9.

36. Coquet JM, et al. Interleukin-21-Producing CD4(+) T Cells Promote Type 2 Immunity to House Dust Mites. Immunity. 2015;43(2):318-330

37. Yuan MJ, Wang T. Advances of the interleukin-21 signaling pathway in immunity and angiogenesis. Biomed Rep. 2016;5(1):3-6.

38. Zeng R, Spolski R, Casas E, Zhu W, Levy DE, Leonard WJ. The molecular basis of IL-21-mediated proliferation. Blood. 2007;109(10):4135-4142.

39. Asao $\mathrm{H}$, et al. Cutting edge: the common gamma-chain is an indispensable subunit of the IL-21 receptor complex. J Immunol. 2001;167(1):1-5.

40. Garty BZ, Ben-Baruch A, Rolinsky A, Woellner C, Grimbacher B, Marcus N. Pneumocystis jirovecii pneumonia in a baby with hyper-IgE syndrome. Eur J Pediatr. 2010;169(1):35-37.

41. Kotlarz D, et al. Loss-of-function mutations in the IL-21 receptor gene cause a primary immunodeficiency syndrome. $J$ Exp Med 2013;210(3):433-443.

42. Kubota M, et al. [Pneumocystis carinii pneumonia in a patient with hyper-IgE syndrome]. Nihon Kokyuki Gakkai Zasshi. 2007;45(5):394-398

43. Kolls JK, et al. IFN-gamma and CD8+ T cells restore host defenses against Pneumocystis carinii in mice depleted of CD4+ T cells. J Immunol. 1999;162(5):2890-2894

44. Pociask DA, et al. IL-22 is essential for lung epithelial repair following influenza infection. Am J Pathol. 2013;182(4):1286-1296

45. Freeman AF, Holland SM. The hyper-IgE syndromes. Immunol Allergy Clin North Am. 2008;28(2):277-291.

46. Freeman AF, et al. Pneumocystis jiroveci infection in patients with hyper-immunoglobulin E syndrome. Pediatrics. 2006;118(4):e1271-e1275

47. Yeste A, et al. IL-21 induces IL-22 production in CD4+ T cells. Nat Commun. 2014;5:3753.

48. Ramirez JM, et al. Activation of the aryl hydrocarbon receptor reveals distinct requirements for IL-22 and IL-17 production by human T helper cells. Eur J Immunol. 2010;40(9):2450-2459.

49. Sonnenberg GF, Fouser LA, Artis D. Functional biology of the IL-22-IL-22R pathway in regulating immunity and inflammation at barrier surfaces. Adv Immunol. 2010;107:1-29.

50. Shellito JE, Tate C, Ruan S, Kolls J. Murine CD4+ T lymphocyte subsets and host defense against Pneumocystis carinii. J Infect Dis. 2000;181(6):2011-2017

51. Zheng M, et al. CD4+ T cell-independent DNA vaccination against opportunistic infections. J Clin Invest. 2005;115(12):3536-3544

52. Eddens T, et al. Eosinophils Contribute to Early Clearance of Pneumocystis murina Infection. J Immunol. 2015;195(1):185-193. 